\title{
Inpatient Opioid Withdrawal Management of Street Children and Adolescents Admitted to Child and Adolescent Psychiatric Ward: A Preliminary Case Series
}

\author{
Mahboubeh Firouzkouhi Moghadam,, ${ }^{1,2}$ Seyed-Sepehr Hashemian, ${ }^{3}$ Masoud Pishjoo, ${ }^{4}$ Sanaz \\ Ghasemi, ${ }^{5}$ Ahmad Hajebi, ${ }^{6}$ and Alireza Noroozi ${ }^{7,}$, \\ ${ }^{1}$ Child and Adolescent Psychiatry Department, Zahedan University of Medical Sciences, Zahedan, IR Iran \\ ${ }^{2}$ Research Center for Children and Adolescents Health, Zahedan University of Medical Sciences, Zahedan, IR Iran \\ ${ }^{3}$ Student research committee, Baqiyatallah University of Medical Sciences, Tehran, IR Iran \\ ${ }^{4}$ General Practitioner, Zahedan University of Medical Sciences, Zahedan, IR Iran \\ ${ }^{5}$ Child and Adolescent Psychiatric Ward, Ali Ebne Abitaleb Hospital, Zahedan, IR Iran \\ ${ }^{6}$ Addiction and High Risk Behavior Research Center, Tehran Institute of Psychiatry, Faculty of Behavioral Sciences and Mental Health, Iran University of Medical Sciences \\ (IUMS), Tehran, IR Iran \\ ${ }^{7}$ School of Advanced Technologies in Medicine, Tehran University of Medical Sciences (TUMS), Tehran, IR Iran \\ "Corresponding author: Alireza Noroozi, School of Advanced Technologies in Medicine, Tehran University of Medical Sciences (TUMS), Tehran, IR Iran. Tel: +98-2181454963, \\ E-mail: a_r_noroozi@yahoo.com
}

Received 2015 December 23; Revised 2016 April 03; Accepted 2016 April 12

\begin{abstract}
Background: About 10 million children worldwide live or work on the street. International reports estimate the prevalence of substance use among street children to be between $25 \%$ - 90\%, which is who were referredntal disorders and high-risk behaviors.

Objectives: The objective of this study was to report the outcomes of assisted withdrawal of opioid-dependent vulnerable children and adolescents who were referred to child and adolescent psychiatric ward of Ali Ebne Abitaleb hospital, an academic hospital in Zahedan city.

Methods: Clinical chart abstractions were performed on a convenience sample of 40 serial opioid-dependent street children and adolescents (mean age: $11.14 \pm 3.6$ years) who were referred to child and adolescent psychiatric ward of Ali Ebne Abitaleb treatment and research center from November 2014 to May 2015. The demographic data, drug use history, comorbid physical and psychiatric conditions, symptomatology of opioid withdrawal syndrome, pharmacotherapies and psychosocial services, length of hospital stay, and any adverse events were extracted from the patients' files using a checklist developed by the authors.

Results: Twenty-four (60\%) patients were male, and 16 (40\%) were female. The main drug used by all patients was opioids. Heroin Kerack (which has a street name of crystal in southeast Iran) was the most common (75\%) drug of use, followed by opium (10\%) and opium residue (7.5\%). None of the participants self-reported using injected drugs. The high rate of a lack of eligibility for guardianship was documented among parents (87.5\%) mainly due to their use of illegal drugs. Musculoskeletal pain and diarrhea were the most common withdrawal symptoms of the patients upon admission. The mean length of stay was 10.8 ( \pm 7.30$)$ days, and no significant adverse events were reported during the symptomatic treatment of opioid withdrawal syndrome.

Conclusions: To our knowledge, this is the first study to report on the safety and feasibility of inpatient symptomatic pharmacological treatment for assisted withdrawal among opioid-dependent children and adolescents in Iran. More well-designed studies to investigate the long-term outcomes of opioid treatment among children are warranted.
\end{abstract}

Keywords: Vulnerable Children, Substance Use, Assisted Withdrawal, Inpatient

\section{Background}

Tens of millions of children around the world work or live on the street (1). It has been estimated that about $25 \%$ $90 \%$ of street children (which was defined as people under 18 years of age) who live or work on the streets (2) use drugs in their daily lives (3). A recent meta-analysis of 22 studies from 22 low-income countries reported that $60 \%$ of street children have a lifetime history of drug use; inhalants were the most common substances used, followed by tobacco, alcohol, and marijuana (4). Most of these street children initiate their substance use with alcohol, tobacco, and inhalants due to the legal availability of these substances (47). Factors such as age, sex, duration of time spent on the street, and social systems affect the pattern of substance use among street youth (8). 
High rates of substance use involvement among street children in Iran have been documented in several studies. One investigation on street children recruited from various areas of Tehran showed a lifetime prevalence of smoking of $36 \%$, while the rates at which street children use alcohol and other substances were $8 \%$ and $3-4 \%$, respectively; these The treatment setting was child more prevalent among boys than girls (9). Because of their lifestyle, street children are exposed to sexual and physical abuse, which leaves them susceptible to mental disorders, such as post-traumatic stress disorder (PTSD) and depression (10). Ghasemzade (2003) reported high rates (37\%) of addiction, selling drugs (41\%), depression (45\%), a lifetime history of sexual abuse (50\%), and physical health problems, including skin lesions (82\%), low weight and height (80\%), and anemia (84\%), among 75 street children aged 14 - 19 in 2001 in Tehran (11).

Despite high rates of substance use disorders among street children, there is little evidence regarding the standard treatment for this sub-population in terms of the treatment setting and modalities. While it has been accepted that the treatment of children with substance use disorders should take place in less restrictive settings than those traditionally recommended for adults $(12,13)$, unique factors among these children, such as substance use within the family, the high rate of comorbid conditions, and the low willingness and motivation of parents or caregivers to cooperate with treatment, necessitate the use of inpatient settings.

The Iranian government ratified regulations for addressing the multidimensional needs of street children in 2005. These regulations define a street child as someone under 18 years of age who for a limited or unlimited period of time lives on the street, including either children who are in contact with their families and have a home to return to or children who make the street their home and have minimal or no relationship with their families. According to these regulations, the state welfare organization (SWO) is considered the main organization for providing housing and support services in Iran and also coordinates 10 other organizations, which are appointed to provide a range of services from legal assistance to healthcare (14).

Following some reports on the high prevalence of substance use among street children in Zahedan city, the drug control coordinating councils of the Sistan and Balouchestan provinces, the provincial welfare organization, and Zahedan University of Medical Sciences (ZUMS) implemented an urgent plan for police to gather street children and transfer them to foster care centers of local welfare organizations. Any children who suffered from withdrawal symptoms should be referred to child and adolescent psychiatric ward of Ali Ebne Abitaleb Hospital, which is affiliated with ZUMS.

\section{Objectives}

Here, we present the preliminary results of inpatient opioid withdrawal outcomes of these street children during hospitalization.

\section{Methods}

\subsection{Treatment Setting}

The treatment setting was child and adolescent psychiatric ward of Ali Ebne Abitaleb academic general hospital. The ward consisted of 10 beds in four rooms, one isolation room, one playroom equipped with a television (TV) and toys, and one time-out room. All rooms and corridors of the ward were monitored by closed-circuit TV.

The ward was staffed with eight nurses, five nursing aides, and one master-level clinical psychologist, who provided treatment services for the study participants under the direct supervision of one child and adolescent psychiatrist. This is an academic ward of child and adolescent psychiatry that occasionally includes rotating residents who are completing their adult general psychiatric training at ZUMS. Only one such resident participated in the treatment of the study participants during the study period.

The child and adolescent psychiatric outpatient clinic of the hospital is active four days per week and provided aftercare services for these patients after they were discharged from the ward.

\subsection{Participants}

Data were extracted from the inpatient files of the first 40 serial cases of street opioid-dependent children admitted to child and adolescent psychiatric ward of Ali Ebne Abitaleb treatment and research center, which was affiliated with ZAUMS, in Zahedan, the center of the Sistan and Balouchestan provinces in southeast Iran, from November 2014 to May 2015. The study participants were children who had been detained by the police because they lived or worked on the street; the children were transferred to the foster care center of the SWO because of their parents' incompetency for guardianship, which was mainly due to substance use disorders. At the foster care center, children and adolescents who were identified as being in need of treatment for a substance use disorder were referred to child and adolescent psychiatric ward. The study participants were all under the guardianship of the province's 
attorney general and were therefore referred to the hospital with a court order that provided consent for all necessary treatment interventions. The procedures and treatment services of the ward were explained to all participants older than 7 years, and their informed consent was obtained. The study was approved by the ethics committee of ZAUMS.

All admitted patients were under 17 years old. A majority of the participants had families and a regular dwelling, patients was opioids. did not and/or spent the night in places not intended as residences, such as the street, parks, or abandoned buildings. The common characteristic of all participants was spending many hours each day on the streets.

Complete personal and familial histories were taken after admission. Mental and physical examinations were also conducted. The current substance dependence disorder was diagnosed based on DSM-IV-TR criteria and evidence of actively using a substance within the last 30 days.

Clonidine, ibuprofen, and hydroxyzine were used for the symptomatic treatment of opioid withdrawal. In this study, clonidine was initiated at $0.1 \mathrm{mg} /$ per day in two divided doses, and then the dose was increased to $0.4 \mathrm{mg} /$ day given in 2 -3 divided doses based on the severity of the withdrawal symptoms on days 2 - 4 following admission. All clonidine doses were delivered after blood pressure had been controlled, which was indicated by a systolic blood pressure $>90 \mathrm{mmHg}$. The participants' assisted withdrawal regimens were chosen based on the severity of their withdrawal symptoms.

Complaints of musculoskeletal pain were managed with ibuprofen. Either syrup or tablet formulations of ibuprofen were prescribed at doses of 4 - $10 \mathrm{mg} / \mathrm{kg}$ four to six times a day with a maximum dose of no more than 1200 $\mathrm{mg} /$ day. Hydroxyzine was administered at a dose of $1 \mathrm{mg} / \mathrm{kg}$ three to four times per day to control nausea and insomnia. Patients who developed severe diarrhea and/or vomiting received rehydration treatment via a half-normal intravenous saline solution.

Some children suffered from comorbid physical and psychiatric disorders. This group received additional pharmacotherapies based on the type of comorbidity. The study participants also were provided with psycho-education for coping with cravings and anger management.

\subsection{Data Extraction and Analysis}

Data were gathered through psychiatric interviews and physical examinations. The withdrawal symptoms were documented by an child and adolescent psychiatrist, who also performed the children's physical examinations. The study data were analyzed using the statistical package for the social sciences (SPSS), version 20, with the Chi- squared test. All analyses were two-tailed, and a P-value < 0.05 was considered statistically significant.

\section{Results}

Forty consecutively admitted, opioid-dependent street children's and adolescents' clinical charts were reviewed. Twenty-four (60\%) patients were male, and 16 (40\%) were female. The mean age of the participants was $11.14 \pm 3.60$ years, with a range from 9 months to 17 years. Thirty-eight (95\%) of the children reported having stable housing, while 2 (5\%) did not. The parents of 35 (87.5\%) of the study participants did not show competency for parenting or guardianship of them at the time of the study. The parenting eligibility was determined by a court order before the children were referred to our hospital. Two (0.5\%) patients admitted a previous history of criminal involvement. A high incidence of a low educational level was documented among the participants' parents, with $55 \%$ of their fathers and $67.5 \%$ of their mothers being illiterate. The demographic characteristics of the participants by gender and age (less than 12 years of age and 12 years and older) are presented in Tables 1 and 2 .

Among the 40 patients, 38 were experiencing opioid withdrawal at the time of hospital admission; the remaining 2 were not because there had been an interval of a few days between their incarceration and hospital admission. The main problem drug for all patients was opioids. The heroin Kerack (which goes by the street name of crystal in southeast Iran) was the most common (70\%) drug of use, followed by opium (10\%) and opium residue (7.5\%). The main drug of use was not significantly different according to gender or age group $(\mathrm{P}>0.05)$ (Table 2).

Significant comorbid physical and mental health problems were observed in 9 (22.5\%) patients; 5 (12.5\%) had psychiatric comorbidities. One child was diagnosed with bipolar mood disorder with psychotic features. He had a history of childhood physical and sexual abuse and suicidal attempts. He did not show progress on polypsychopharmacotherapy and finally received eight sessions of electroconvulsive therapy during his hospital stay. One child had amphetamine-type stimulant-induced psychosis. One participant each was diagnosed with attention deficit hyperactivity disorder (ADHD) alone and conduct disorder alone, while another child suffered from both ADHD and conduct disorder concurrently. Four (10\%) had significant physical comorbidities, including 1 (2.5\%) seizure disorder, 2 (5\%) pneumonia and 1 (2.5\%) endocarditis superimposed on a ventricular septal defect (VSD). Twenty-two (55\%) had pediculosis, which was treated with 1\% Lindane shampoo and hair dressings. 
Table 1. The Demographic Characteristics of the Study Participants and their Parents by Sex and Age ${ }^{\mathrm{a}}$

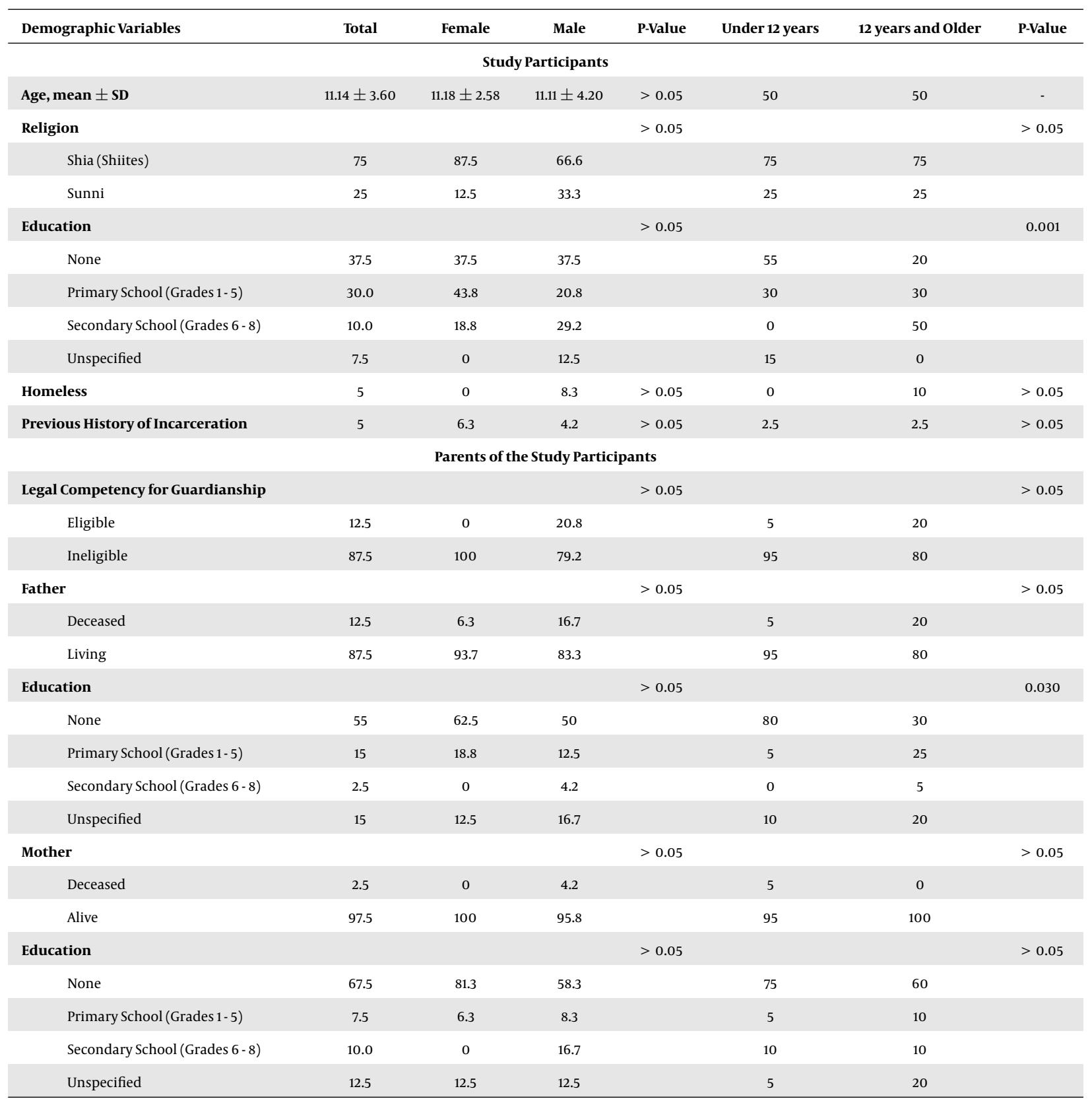

${ }^{\mathrm{a}}$ Values are expressed as \% unless otherwise indicated.

The mean length of hospital stay was $10.8 \pm 7.30$ (2 48) days, and the mean duration of withdrawal signs and symptoms was $1.63 \pm 0.94$ days (a few hours-3 days). Musculoskeletal pain and diarrhea were the most commonly reported withdrawal symptoms during the hospital stay. Withdrawal signs and symptoms were not significantly different by gender or age group $(\mathrm{P}>0.05)$. Furthermore, there was no significant relationship between the duration of withdrawal and gender or age group $(\mathrm{P}>0.05)$ (Table 3$)$.

\section{Discussion}

The present study was conducted in 40 street children and adolescents who used drugs and had been referred to 
Table 2. Pattern of Drug Use and Comorbidities ${ }^{\mathrm{a}}$

\begin{tabular}{|c|c|c|c|c|c|c|c|}
\hline Demographic Variables & Total & Female & Male & P-Value & Under 12 Years & 12 Years and Older & P-Value \\
\hline Main Drug of Use & & & & $>0.05$ & & & $>0.05$ \\
\hline Heroin & 5.0 & 6.3 & 4.2 & & 5 & 15 & \\
\hline Opium & 10.0 & 6.3 & 12.5 & & 5 & 15 & \\
\hline Opium residue (Shireh) & 7.5 & 0 & 12.5 & & 10 & 5 & \\
\hline Tramadol & 0 & 0 & 0 & & 0 & 0 & \\
\hline Methadone & 2.5 & 0 & 4.2 & & 5 & 0 & \\
\hline Heroin Kerack & 75.0 & 87.6 & 64.9 & & 75 & 75 & \\
\hline Polysubstance Use & & & & $>0.05$ & & & $>0.05$ \\
\hline No & 65.0 & 43.7 & 79.2 & & 75 & 55 & \\
\hline Yes & 35.0 & 56.3 & 20.8 & & 25 & 45 & \\
\hline Two drugs & 27.5 & 43.8 & 16.7 & & 15 & 40 & \\
\hline Three drugs & 7.5 & 12.5 & 4.2 & & 10 & 5 & \\
\hline Polysubstance Forms & & & & $>0.05$ & & & $>0.05$ \\
\hline Heroin Kerack + Opium & 35.7 & 36.3 & 33.3 & & 40 & 33.4 & \\
\hline Heroin Kerack + Methamphetamine & 28.5 & 27.3 & 33.3 & & 40 & 22.2 & \\
\hline Heroin Kerack + Opium residue & 14.2 & 9.1 & 33.3 & & 0 & 22.2 & \\
\hline Heroin Kerack + Cannabis & 7.1 & 9.1 & 0 & & 0 & 11.1 & \\
\hline Heroin Kerack + Opium + Opium residue & 7.1 & 9.1 & 0 & & 0 & 11.1 & \\
\hline Heroin Kerack + Opium + Heroin & 7.1 & 9.1 & 0 & & 20 & 0 & \\
\hline Route of Administration & & & & $>0.05$ & & & $>0.05$ \\
\hline Smoking & 85 & 100 & 79.1 & & 80 & 95 & \\
\hline Swallowing & 15 & 0 & 20.9 & & 20 & 5 & \\
\hline Sniffing & 0 & 0 & 0 & & 0 & 0 & \\
\hline Injecting & 0 & 0 & 0 & & 0 & 0 & \\
\hline Comorbid Conditions & & & & $>0.05$ & & & $>0.05$ \\
\hline No & 77.5 & 87.5 & 70.8 & & 85 & 70 & \\
\hline Yes & 22.5 & 12.5 & 29.2 & & 15 & 30 & \\
\hline Physical (Other than pediculosis) & 10.0 & 6.3 & 12.5 & & 5 & 15 & \\
\hline Psychiatric & 12.5 & 6.3 & 16.7 & & 10 & 15 & \\
\hline No. of Previous Hospitalizations & & & & $>0.05$ & & & $>0.05$ \\
\hline Zero & 97.5 & 100 & 95.8 & & 100 & 95 & \\
\hline One & 0 & 0 & 0 & & 0 & 0 & \\
\hline Two & 2.5 & 0 & 4.2 & & 0 & 5 & \\
\hline
\end{tabular}

${ }^{\mathrm{a}}$ Values are expressed as \%.

a psychiatric ward for children and adolescents. Although a small percentage of these children perceived themselves as homeless, we documented other factors, such as the death or lack of a qualified guardian and parental illiteracy or a very low literacy level, which could have contributed to the participants' situation as substance-using youth. This observation is consistent with international studies that have reported the complex needs of families referred to child welfare services because of parental substance use and child neglect (15-17). The high rate of parenting incompetency indicates that any medical and psychiatric interventions initiated among this population must be imple- 
Table 3. Signs and Symptoms of Opioid Withdrawal Syndrome Among Participants

\begin{tabular}{|c|c|c|c|c|c|c|c|}
\hline Demographic Variables & Total & Female & Male & P-Value & Under 12 Years & 12 years and Older & P-Value \\
\hline Signs and symptoms & & & & $>0.05$ & & & $>0.05$ \\
\hline Musculoskeletal pain & 77.5 & 87.5 & 70.8 & & 70 & 85 & \\
\hline Diarrhea & 47.5 & 62.5 & 33.3 & & 45 & 50 & \\
\hline Runny nose & 27.5 & 43.7 & 16.6 & & 30 & 25 & \\
\hline Abdominal pain & 20 & 37.5 & 8.3 & & 20 & 20 & \\
\hline Yawning & 12.5 & 12.5 & 16.6 & & 20 & 15 & \\
\hline Restlessness & 17.5 & 0 & 29.1 & & 15 & 15 & \\
\hline Aggression & 7.5 & 0 & 12.5 & & 5 & 10 & \\
\hline Drowsiness & 2.5 & 0 & 4.1 & & 5 & 0 & \\
\hline Duration of the Withdrawal Syndrome (Days) & & & & $>0.05$ & & & $>0.05$ \\
\hline Mean \pm SD & $1.63 \pm 0.94$ & $1.68 \pm 0.94$ & $1.59 \pm 0.95$ & & $1.66 \pm 0.96$ & $1.60 \pm 0.94$ & \\
\hline Range & $0-3$ & $0-3$ & $0-3$ & & $0-3$ & $0-3$ & \\
\hline
\end{tabular}

${ }^{\mathrm{a}}$ Values are expressed as \% unless otherwise indicated.

Table 4. Treatment Services ${ }^{\mathrm{a}}$

\begin{tabular}{|c|c|c|c|c|c|c|c|}
\hline Demographic Variables & Total & Female & Male & P-Value & Under 12 Years & 12 Years and Older & P-Value \\
\hline Length of hospital stay, days & & & & $>0.05$ & & & $>0.05$ \\
\hline Mean \pm SD & $10.80 \pm 7.30$ & $9.94 \pm 5.06$ & $11.38 \pm 8.53$ & & $9.40 \pm 3.81$ & $12.20 \pm 9.52$ & \\
\hline Range & $2-48$ & $2-23$ & $3-48$ & & $2-15$ & $3-48$ & \\
\hline \multicolumn{8}{|c|}{ Pharmacotherapies } \\
\hline Withdrawal management & & & & & & & $>0.05$ \\
\hline Clonidine & 75.0 & 100 & 52.5 & & 70 & 80 & \\
\hline NSAIDs (ibuprofen) & 75.0 & 87.5 & 70.8 & & 55 & 90 & \\
\hline Hydroxyzine & 70.0 & 68.7 & 70.8 & & 50 & 90 & \\
\hline Benzodiazepines (Lorazapam, clonazepam) & 7.5 & 0 & 12.5 & & 10 & 5 & \\
\hline Methadone & 10.0 & 0 & 16.6 & & 0 & 0 & \\
\hline No medication & 2.5 & 0 & 4.1 & & 5 & 0 & \\
\hline Other pharmacotherapies & & & & $>0.05$ & & & $>0.05$ \\
\hline Olanzapine & 7.5 & 0 & 12.5 & & 10 & 5 & \\
\hline Risperidone & 12.5 & 0 & 20.8 & & 10 & 15 & \\
\hline VPA & 7.5 & 12.5 & 4.1 & & 0 & 15 & \\
\hline $\mathrm{CBZ}$ & 2.5 & 0 & 4.1 & & 0 & 5 & \\
\hline Psychosocial Services & & & & $>0.05$ & & & $>0.05$ \\
\hline $\begin{array}{l}\text { Coping with craving and anger } \\
\text { management psycho-education }\end{array}$ & 95 & 93.8 & 95.8 & & 90 & 100 & \\
\hline
\end{tabular}

${ }^{\mathrm{a}}$ Values are expressed as \% unless otherwise indicated.

mented within the context of a comprehensive program to provide parental substance abuse treatment, psychoso- cial support, literacy education initiatives, legal assistance, and foster care. 
In this study, most (75\%) patients were taking heroin Kerack, followed by opium and opium residue; the most common route of administration was smoking, which was inconsistent with international studies that have reported inhalants, tobacco and alcohol (4), and methamphetamine $(18,19)$ as the most commonly used substances by street children in different countries. This variation may be explained by the ease of availability of opioids in the Sistan and Balouchestan province of Iran due to the proximity of Afghanistan, the main producer of illegal opioids in the world. All study participants used drugs through routes other than injection, which was in line with findings from other low-income countries $(8,20)$. About onethird of these children had used more than one substance, which reflects a high intensity of drug involvement in this population.

Musculoskeletal pain, diarrhea, and runny nose were the most common signs and symptoms observed during the withdrawal period; there was no significant difference in withdrawal length or symptomatology by age and gender. For the medical management of withdrawal, clonidine, ibuprofen, and hydroxyzine were the most frequently used medications. The symptomatic treatment of opioid withdrawal was well tolerated by the children, and no severe adverse events were seen.

One head-to-head trial that compared clonidine and buprenorphine in a community-based treatment program for opioid dependence among adolescents showed a higher efficacy for buprenorphine in terms of treatment retention and negative urine tests (21). Little evidence exists regarding the use of maintenance medications to treat opioid dependence. Methadone maintenance treatment for opioid dependence among patients younger than 18 years is highly regulated, and its use is limited to very severe cases (22). In addition, buprenorphine might have some advantages over methadone in terms of its adverse effects. In a multi-site trial of adolescents and young adults, buprenorphine maintenance increased retention and decreased opioid-positive urine tests compared to patients who received two weeks of buprenorphine detoxification only (23). Another case series study indicated the feasibility and safety of community-based extended-release naltrexone shots that were given to adolescents and young adults each month for four months in a community-based setting (24). The use of pharmacotherapies to manage pediatric opioid withdrawal is in its early stages in Iran. More studies are currently needed to determine the status of opioid pharmacotherapies for symptomatic withdrawal in terms of their effectiveness and costs.

The high rate of comorbid physical and psychiatric disorders observed in this study has important clinical im- plications. First, a clinician working with street children might encounter substance use issues that co-occur with other mental disorders and therefore should be prepared for this possibility. Second, the identification and treatment of physical health issues are crucial while working with this population. A trend toward higher levels of physical and psychiatric comorbidities was seen among boys in this clinical sample, which was not significant due to the small sample size. More studies with larger sample sizes will therefore be needed to determine any differences in the pattern of comorbidities.

Practical implementation issues identified in this study included work load, costs, insurance coverage, administrative issues, and insufficient inter-sectoral collaboration. Cost and insurance coverage issues were also prominent. There were limitations of this study, including its observational design without a control group, the absence of standardized questionnaires to monitor outcomes, and limitations of the outcomes to the inpatient period.

The study suggests that inpatient withdrawal management with clonidine, antihistamines, and non-steroidal anti-inflammatory drugs could be feasible for and well tolerated by children and adolescents with opioid dependence during the inpatient period. To develop standards of care for opioid treatment in this population, further studies that test the efficacy of opioids agonist medications on the severity of withdrawal, the length of stay, and the success rate of post-discharge treatment follow-ups are warranted.

\section{Acknowledgments}

The authors would like to thank the study participants as well as the staff of child and adolescent psychiatric ward of Ali Ebne Abitaleb treatment and research center, which is affiliated with Zahedan University of Medical Sciences. We also thank the SWO staff and the juridical system staff of the Sistan and Balouchestan province.

\section{Footnote}

Authors' Contribution: Study concept and design, Mahboubeh Firouzkouhi and Alireza Noroozi; acquisition of data, Sanaz Ghasemi; analysis and interpretation of data, Mahboubeh Firouzkhouhi, Seyed-Sepehr Hashemian, and Masoud Pishjoo; drafting of the manuscript, Alireza Noroozi, Mahboubeh Firouzkouhi, and Seyed-Sepehr Hashemian; critical revision of the manuscript for important intellectual content, Alireza Noroozi, Mahboubeh Firouzkouhi, Seyed-Sepehr Hashemian, and Ahmad Hajebi; statistical analysis, Masoud Pishjoo and Seyed-Sepehr 
Hashemian; administrative, technical, and material support, Alireza Noroozi and Mahboubeh Firouzkouhi; study supervision, Alireza Noroozi.

\section{References}

1. UNICEF. The state of the world's children 2006: excluded and invisible. Unicef; 2005.

2. UNICEF. State of the world's children: Celebrating 20 years of the convention on the rights of the child. Unicef; 2009.

3. WHO . A training package on substance use, sexual and reproductive health including HIV|AIDS and STDs: Module 3, Understanding substance use among street children. ; 2000.

4. Embleton L, Mwangi A, Vreeman R, Ayuku D, Braitstein P. The epidemiology of substance use among street children in resourceconstrained settings: a systematic review and meta-analysis. Addiction. 2013;108(10):1722-33. doi: 10.1111/add.12252. [PubMed: 23844822].

5. Bal B, Mitra R, Mallick AH, Chakraborti S, Sarkar K. Nontobacco substance use, sexual abuse, HIV, and sexually transmitted infection among street children in Kolkata, India. Subst Use Misuse. 2010;45(10):1668-82. doi: 10.3109/10826081003674856. [PubMed: 20590379].

6. Inciardi JA, Surratt HL. Children in the streets of Brazil: drug use, crime, violence, and HIV risks. Subst Use Misuse. 1998;33(7):1461-80. [PubMed: 9657412]

7. Nada KH, Suliman el DA. Violence, abuse, alcohol and drug use, and sexual behaviors in street children of Greater Cairo and Alexandria, Egypt. AIDS. 2010;24 Suppl 2:S39-44. doi: 10.1097/01.aids.0000386732.02425.d1. [PubMed: 20610947].

8. Ahamad K, Debeck K, Feng C, Sakakibara T, Kerr T, Wood E. Gender influences on initiation of injecting drug use. Am J Drug Alcohol Abuse. 2014;40(2):151-6. doi: 10.3109/00952990.2013.860983. [PubMed: 24405226].

9. Ahmad Khaniha AR, Hakim Shooshtari M, Mohammadian M, Bidaki R, Pourrashidi Boshrabadi A. Familial characteristics of street children in tehran, iran. Iran J Psychiatry Behav Sci. 2014;8(2):86-9. [PubMed: 25053962].

10. Kamieniecki GW. Prevalence of psychological distress and psychiatric disorders among homeless youth in Australia: a comparative review. Aust N Z J Psychiatry. 2001;35(3):352-8. [PubMed: 11437809].

11. FG . Street children in Tehran. Social Welfare. 2003;2(7):249-66.

12. Bukstein OG, Bernet W, Arnold V, Beitchman J, Shaw J, Benson RS, et al. Practice parameter for the assessment and treatment of children and adolescents with substance use disorders. JAm Acad Child Adolesc Psychiatry. 2005;44(6):609-21. [PubMed: 15908844].

13. Klaehn JR, Neilson RH. Synthesis and characterization of mixedsubstituent N-silylphosphoranimines. Inorg Chem. 2002;41(22):585965. [PubMed:12401094].

14. Cabinet I. Regulations for arrangement of street children ratified by cabinet No. 32386-227170. Cabinet Meeting. 2005.

15. Douglas-Siegel JA, Ryan JP. The effect of recovery coaches for substance-involved mothers in child welfare: impact on juvenile delinquency. J Subst Abuse Treat. 2013;45(4):381-7. doi: 10.1016/j.jsat.2013.05.010. [PubMed: 23856594].

16. Saldana L. An integrated intervention to address the comorbid needs of families referred to child welfare for substance use disorders and child neglect: Fair pilot outcomes. Child welfare. 2015;94(4).

17. McGillicuddy NB, Rychtarik RG, Papandonatos GD. Skill training versus 12-step facilitation for parents of substance-abusing teens. J Subst Abuse Treat. 2015;50:11-7. doi: 10.1016/j.jsat.2014.09.006. [PubMed: 25306932]

18. Saddichha S, Linden I, Krausz MR. Physical and Mental Health Issues among Homeless Youth in British Columbia, Canada: Are they Different from Older Homeless Adults?. J Can Acad Child Adolesc Psychiatry. 2014;23(3):200-6. [PubMed: 25320613].

19. Smart RG, Adlaf EM. Substance use and problems among Toronto street youth. BrJ Addict. 1991;86(8):999-1010. [PubMed: 1912754].

20. Hadland SE, Marshall BD, Kerr T, Zhang R, Montaner JS, Wood E. A comparison of drug use and risk behavior profiles among younger and older street youth. Subst Use Misuse. 2011;46(12):1486-94. doi 10.3109/10826084.2011.561516. [PubMed: 21417557].

21. Marsch LA, Bickel WK, Badger GJ, Stothart ME, Quesnel KJ, Stanger $C$, et al. Comparison of pharmacological treatments for opioiddependent adolescents: a randomized controlled trial. Arch Gen Psychiatry. 2005;62(10):1157-64. doi: 10.1001/archpsyc.62.10.1157. [PubMed: 16203961].

22. Mokri A, Noroozi A. National protocol for treatment of opioid dependence with methadone. Ministry of health and medical education 2015

23. Woody GE, Poole SA, Subramaniam G, Dugosh K, Bogenschutz M, Abbott $\mathrm{P}$, et al. Extended vs short-term buprenorphine-naloxone for treatment of opioid-addicted youth: a randomized trial JAMA. 2008;300(17):2003-11. doi: 10.1001/jama.2008.574. [PubMed: 18984887].

24. Fishman MJ, Winstanley EL, Curran E, Garrett S, Subramaniam G. Treatment of opioid dependence in adolescents and young adults with extended release naltrexone: preliminary case-series and feasibility. Addiction. 2010;105(9):1669-76. doi: 10.1111/j.13600443.2010.03015.x. [PubMed: 20626723]. 